\title{
Review Article \\ Role of the Renin-Angiotensin System and Aldosterone on Cardiometabolic Syndrome
}

\author{
P. Stiefel, A. J. Vallejo-Vaz, S. García Morillo, and J. Villar \\ Unidad clínico-experimental de Riesgo Vascular (UCERV-UCAMI), IBIS. Hospital Universitario Virgen del Rocío, SAS, \\ Universidad de Sevilla, CSIC Avenida, 41011 Sevilla, Spain \\ Correspondence should be addressed to P. Stiefel, stiefel@cica.es
}

Received 31 December 2010; Revised 24 March 2011; Accepted 29 April 2011

Academic Editor: Vanessa Ronconi

Copyright ( $\odot 2011$ P. Stiefel et al. This is an open access article distributed under the Creative Commons Attribution License, which permits unrestricted use, distribution, and reproduction in any medium, provided the original work is properly cited.

Aldosterone facilitates cardiovascular damage by increasing blood pressure and through different mechanisms that are independent of its effects on blood pressure. In this respect, recent evidence involves aldosterone in the pathogenesis of metabolic syndrome. Although this relationship is complex, there is some evidence suggesting that different factors may play an important role, such as insulin resistance, renin-angiotensin-aldosterone system, oxidative stress, sodium retention, increased sympathetic activity, levels of free fatty acids, or inflammatory cytokines and adipokines. In addition to the classical pathway by which aldosterone acts through the mineralocorticoid receptors leading to sodium retention, aldosterone also has other mechanisms that influence cardiovascular tissue remodelling. Finally, overweight and obesity promote the adrenal secretion of aldosterone, increasing the predisposition to type 2 diabetes mellitus. Further studies are needed to better establish therapeutic strategies that act on the blockade of mineralocorticoid receptor in the treatment and prevention of cardiovascular diseases related to the excess of aldosterone and the metabolic syndrome.

\section{Introduction}

Prevalence of hypertension and obesity is increasing around the world, and data from NHANES III show that hypertension increases parallel to a rising body mass index [1]. An increase in abdominal obesity, also when only moderate overweight exits or even if there is no overweight, plays a key role on cardiometabolic diseases [2]. This increase in abdominal obesity is associated with carbohydrate and lipid metabolism disorders and with elevation of blood pressure levels. On the contrary, a rising subcutaneous adiposity does not seem to be accompanied by any systemic complication of obesity [3]. Most studies link abdominal obesity and cardiometabolic disorders with the inflammatory status and oxidative stress that lead to the development of insulin resistance $[4,5]$. Insulin resistance also plays a major role in the development of metabolic syndrome and type 2 diabetes mellitus [6]. Moreover, hypertension usually occurs at the same time with other risk factors: insulin resistance, central obesity, dyslipidemia, and carbohydrate disorders, to constitute the so-called cardiometabolic syndrome.
Aldosterone may lead to cardiovascular damage through different mechanisms that are independent on its hemodynamic effects on blood pressure. Thus, many recent studies involve aldosterone in the pathogenesis of the cardiometabolic syndrome [7]; although this relationship is complex and it is not well established, there is some evidence that different factors could act on it: insulin resistance, reninangiotensin-aldosterone system, oxidative stress, sodium retention and volume overload, increased sympathetic activity, levels of free fatty acids, or inflammatory cytokines and adipokines. Renin-angiotensin-aldosterone system has been linked with obesity-related hypertension [8], and it is also involved in the association among obesity, metabolic syndrome, dyslipidemia, insulin resistance, chronic kidney disease, and hypertension [9]. The classical genomic pathway by which aldosterone acts through the mineralocorticoid receptors are related to sodium retention and volume expansion. But, in addition, aldosterone has nongenomic mechanisms too, acting on cardiovascular tissue remodeling and on central nervous system, and then taking part in the 
development of cardiometabolic syndrome, insulin resistance and hypertension.

\section{Genomic and Nongenomic Effects of Aldosterone (Figure 1)}

The role of aldosterone on gene transcription and consequently on the protein synthesis has been better known since the introduction of molecular biology techniques [10]. Genomic mechanism of action of aldosterone has been traditionally divided into two distinct phases [11-13]. In the first phase, an early (from 30 minutes onwards) activation or inactivation of different genes takes place; these genes can modulate the activity of sodium and potassium transporters, mainly the $\mathrm{Na} / \mathrm{K}$-ATPase, the sensitive to thiazides $\mathrm{Na} / \mathrm{Cl}$ cotransporter, and the epithelial sodium channel [14, 15]. Different proteins, such as SGK-1, CHIF, Ki-Ras, GILZ, or NDRG2, act in this phase [16-19]. By contrast, aldosterone, in its later phase (from 3 hours), directly modulates the expression levels of various sodium and potassium transporters, leading to a net increase in sodium reabsorption and potassium secretion.

Nevertheless, apart from the classical mechanisms mentioned above, aldosterone also has nongenomic or nonclassical effects, which are independent on the mineralocorticoid receptor and therefore are insensitive to the effect of mineralocorticoid receptor antagonists such as spironolactone. These nongenomic effects of aldosterone (not requiring signaling through the classical pathway including gene activation, transcription, and protein synthesis) were described by Wehling et al. in 1992 [20]. These effects take place quickly (in seconds) and occur in various tissues from both epithelial and nonepithelial origin, such as vascular smooth muscle cells, endothelial cells, cardiac myocytes, kidney cells, and colonic epithelial cells, as well as in cell lines of human mononuclear leukocytes [21]. The nongenomic effects include: regulation of intracellular cations, cell volume, redox status, metabolic signaling, and vascular endothelium-dependent relaxation [22]. In the last years, it is becoming increasingly clear that these nongenomic and not hemodynamic effects of aldosterone constitute an important part of the mechanisms by which aldosterone contributes to the pathogenesis of metabolic syndrome and resistant hypertension [22-24].

Elevated levels of aldosterone, in association with obesity and insulin resistance, promote nongenomic inflammation and oxidative stress, which advance the development of resistant hypertension through a number of mechanisms [9]. In this way, it has been demonstrated that aldosterone can inhibit the endothelium-dependent relaxation by decreasing nitric oxide bioavailability (a consequence of increased reactive oxygen species generation). In addition, perivascular fibrosis induced by aldosterone reduces vascular compliance and increases arterial stiffness, and an increased $\mathrm{Na} / \mathrm{H}$ interchange stimulates vascular smooth muscle cell proliferation $[25,26]$. These actions potentiate the elevation of blood pressure levels that occurs as consequence of classical effects of aldosterone (salt retention and volume expansion), causing severe hypertension that is resistant to treatment unless an appropriate mineralocorticoid receptor antagonist (such as spironolactone or eplerenone) is used as part of the therapeutic strategy.

\section{Aldosterone and Insulin Resistance}

In the last years, we have learnt more about the actions of aldosterone. At present, we know that it plays a role in the pathogenesis of the metabolic syndrome [23] and that elevated levels of aldosterone take part directly in the pathogenesis of insulin resistance and endothelial dysfunction, facilitating a vascular remodeling that ultimately can lead to resistant hypertension in association with obesity and metabolic syndrome. The effects of aldosterone on cardiometabolic syndrome are independent on the action of angiotensin II. Thus, in primary hyperaldosteronism, where low plasma renin activity and angiotensin II levels are found, there are higher levels of plasma glucose and higher prevalence of cardiometabolic syndrome than in essential hypertension [27]. Patients with primary hyperaldosteronism have more cardiovascular events than those with essential hypertension [28].

Our group demonstrated that patients with primary hyperaldosteronism have a greater intima-media thickness and that it was related to plasma levels of aldosterone and aldosterone/plasma renin activity ratio [29]. In addition, plasma levels of aldosterone are associated with cardiometabolic syndrome; Fallo et al. [30] showed that patients with primary hyperaldosteronism had higher levels of plasma glucose and prevalence of cardiometabolic syndrome than those with essential hypertension. Fallo et al. [31] confirmed that the excess of aldosterone has a negative effect on the glucose metabolism; this may explain at least in part the higher number of cardiovascular events that we can observe in primary hyperaldosteronism compared with essential hypertension. In the same way, it is demonstrated that there is an improvement in insulin resistance and that plasma glucose and insulin levels decrease in patients surgically treated of an aldosterone-producing tumor [32]. Similar results have been found with mineralocorticoid receptor blockers in cases of idiopathic hyperaldosteronism. Colussi et al. [33] performed a comparison between patients with essential hypertension and normotensive subjects and showed that a direct relationship exists between levels of aldosterone and insulin resistance or hyperinsulinism; the authors suggest that in hypertensive patients this relationship may contribute both to the persistent elevated blood pressure levels and to an increased cardiometabolic risk. Other two large studies have also indicated that plasma levels of aldosterone but not renin are associated with metabolic syndrome $[34,35]$.

However, Matrozova et al. [36] in their large series did not find differences in carbohydrate or lipid metabolism between a group of 460 cases of primary hyperaldosteronism and a control group of 1363 patients with essential hypertension. Similar findings were obtained from the subanalysis of the Trial of Preventing Hypertension Study [37], with no evidence of higher levels of aldosterone in patients with metabolic syndrome. 


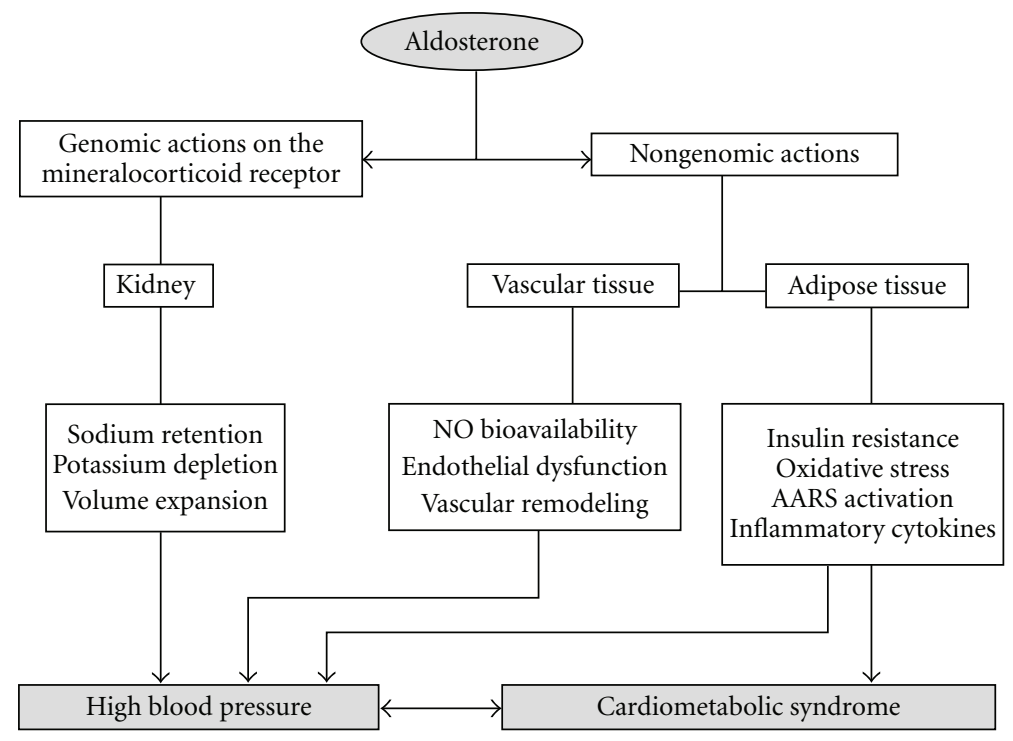

FIGURE 1

The relationship between aldosterone and insulin reported by different studies is also supported by experimental evidences; different mechanisms by which aldosterone may induce insulin resistance have been suggested: effects of hypokalaemia on pancreatic beta-cells, direct effects of aldosterone on insulin receptors, activation of hepatic neoglucogenesis, and effects on $\mathrm{Na}$ /glucose cotransporter [38]. In addition, it has been suggested that human adipocytes can produce a mineralocorticoid releasing factor that promotes the production of aldosterone [39]. Some data support that aldosterone can have a negative effect on the structure and function of the pancreatic beta-cells, due to an increase in inflammation and oxidative stress [23] and to a decrease in insulin sensitivity in human adipocytes [40]. It is also possible that hyperinsulinemia may lead to higher levels of aldosterone [41]; these higher levels of aldosterone may also be related to the association between insulin resistance and the amount of body fat. Fatty acids and adipokines have an important role in the development of insulin resistance [42] and both stimulate the production of aldosterone [43]. Experimental studies also show that adipocytes promote the secretion of aldosterone in the adrenal glands [41].

\section{Renin-Angiotensin-Aldosterone System and Obesity}

Upregulation of renin-angiotensin-aldosterone system, characterized by higher levels of plasma renin activity and aldosterone, has been described in patients with visceral obesity [44]; this improves when patients lose weight [45]. This abnormal regulation of renin-angiotensin-aldosterone system in obesity may result from a primary increase in the production of renin-angiotensin-aldosterone system components or may be the consequence of an alteration in the atrial natriuretic peptide system [46].

The key role of renin-angiotensin-aldosterone system in the regulation of systemic blood pressure and electrolyte ho- meostasis has been well recognized for many years. In addition, in the last decade, its presence in a wide variety of tissues has been described, such as adrenal glands, kidneys, brain, heart, or blood vessels; this suggests the existence of a local renin-angiotensin-aldosterone system that would act as a regulator of several functions in different organs [42]. Local renin-angiotensin-aldosterone system has also been involved in structural and functional pathologic changes that can take place in different organs, by modulating gene expression, growth, fibrosis, and possibly the inflammatory response [43].

Recently, many data support the presence of a local renin-angiotensin-aldosterone system in the adipose tissue too, which may have an important role in the physiological regulation of this tissue and may have also a role in the pathophysiology of obesity and of obesity-related hypertension. Several studies support this hypothesis. The expression of angiotensinogen in human adipose tissue has been demonstrated by studies with cultures of adipocytes and preadipocytes [47]. The expression of angiotensinogen seems to be regulated by free fatty acids, glucocorticoids, and possibly by tumor necrosis factor-alpha [48]. However, although the effects of insulin in the hepatic expression of angiotensinogen are well established, its role in the adipose tissue is controversial.

It has been proven that production of angiotensin II increases during the differentiation process of human preadipocytes. Crandall et al. [49] identified angiotensin II receptors in adipocytes, although the function of these receptors is not established. Angiotensin II may also act on other different cell systems that we can find in the adipose tissue: endothelial cells, smooth muscle cells, sympathetic nerve fibers, lymphocytes, or mononuclear cells. We may then hypothesize that angiotensin II released by adipocytes could have a role in the physiology and pathophysiology of the adipose tissue and even of other tissues closely related to adipocytes. Several studies have found a direct 
relationship between plasma levels of angiotensinogen and body mass index in different populations [50]. Plasma renin activity and angiotensin-converting enzyme have also been correlated positively with body mass index in obese patients [50]. There is much evidence to suggest that angiotensin II modulates the effects of insulin [51]. Renin-angiotensinaldosterone system activation may inhibit the metabolic effects of insulin in the PI3 kinase pathway and at the same time may facilitate its proliferative effects via the MAP kinase pathway [48]. Subjects with insulin resistance constitute a high risk group of patients; some evidence supports a therapeutic approach with AT1 receptor blockers in this group of patients; in experimental models with increased density of AT1 and AT2 receptors (what leads to the development of hypertension and hyperinsulinemia), it has been shown that these effects may be avoided in the short and longterm by blocking AT1 receptors [52]. Similarly, in an experimental model of metabolic syndrome the treatment with angiotensin-receptor blockers can inhibit the development of hyperinsulinemia, hypertension, obesity, heart hypertrophy, and atherosclerosis [51]. Some clinical trials involving angiotensin-converting enzyme inhibitors and angiotensin-receptor blockers showed an improvement in carbohydrate metabolism in hypertensive subjects. Additionally, endothelial dysfunction (predictor of cardiovascular morbimortality) may also be improved by blocking AT1 receptors [51]. Nevertheless, more studies are needed to conclude whether obesity and hypertension are both associated with changes in the genetic expression of renin-angiotensinaldosterone system and to clarify the activity of reninangiotensin-aldosterone system on adipocytes [53].

Although some findings regarding renin-angiotensinaldosterone system in the adipose tissue may be controversial, its implication in the physiology and pathophysiology of this tissue has been confirmed by several functional studies. The influence of angiotensinogen in the development and metabolism of the adipose tissue has been shown in different in vitro and in vivo studies. In vitro functional studies have shown that adipocytes produce angiotensinogen and that a rising adiposity may lead to elevation of plasma renin activity [54]. In addition, levels of angiotensinogen and angiotensin II are elevated in abdominal obesity [55]. Obesity, mainly when associated to metabolic syndrome, is accompanied by a raised sympathetic nervous system activity [46]. This fact constitutes an important factor that increases renin secretion in the kidneys. At the same time, angiotensin II increases sympathetic nervous system activity. And both systems, when activated, lead to an absence of inhibition of the heart natriuretic peptides (which have important biological effects on plasma volume) [28].

4.1. Sympathetic Nervous System and RAAS. Hyperactivity of the sympathetic nervous system plays a key role in the development of different metabolic disorders and hypertension in the cardiometabolic syndrome [56]. The presence of visceral fat (more importantly than peripheral fat) may constitute a major cause of this adrenergic enhancement; the later would be more important in obese subjects than in those with a normal weight, regardless of the presence or absence of hypertension [57]. The augmented levels of angiotensin II in obese patients have been related to the activation of the sympathetic nervous system; however, the physiological mechanisms to explain this relationship are not well established. It seems clear that in central obesity there is an impaired function of baroreceptors and baroreflexes and that this activates compensatory mechanisms to bring back the adrenergic status, such as hyperinsulinism or increased secretion of free fatty acids or leptin $[58,59]$. Low plasma levels of both grhelin and adiponectin lead to a hyperstimulation of the sympathetic nervous system; the infusion of both at the central nervous system in mice reduces the activity of the sympathetic nervous system and counteracts the positive effects of leptin [60].

On the other hand, it has been hypothesized that aldosterone may be a nexus between adiposity and sympathetic nervous system, since it has been shown that aldosterone carries out central actions on adrenergic receptors in various animal models [61]. Although angiotensin II contributes significantly to obesity-related hypertension, more studies are needed to determine whether this is mediated by activation of the sympathetic nervous system, by direct effects on the kidneys or by stimulating the secretion of aldosterone.

In addition, central activation of mineralocorticoid receptor can modulate salt intake [62] and the onset of hypertension mediated by the sympathetic nervous system [63]. Recently, Kontac et al. [64], by applying intraneural electrodes, demonstrated that there is a reversible sympathetic hyperactivation in hypertensive patients with primary hyperaldosteronism, which could accelerate target organ damage in these subjects. An increase in plasma levels of angiotensin II causes a hypothalamic neuronal activation (in the supraoptic and paraventricular nuclei) and a vasopressor effect mediated by neural activation of the sympathetic nervous system (through secretion of oubaoin) [65]. Central blockade of renin-angiotensin-aldosterone system could play a key role in reducing this proadrenergic status; in this respect, it has been observed that the blockade of mineralocorticoid receptor in in vitro studies (by intraventricular brain infusion of an aldosterone-synthetase inhibitor) restores the sympathetic hyperactivity and saline infusionrelated hypertension [66]. These and other studies support the hypothesis that the activation of mineralocorticoid receptor in the brain may increase sympathetic activity, at least in part by activation of cerebral renin-angiotensinaldosterone system. Neurohormonal blockade of peripheral effects of aldosterone with appropriate blockers such as spironolactone may diminish sympathetic activation in hypertensive subjects [67] and patients with cardiometabolic syndrome. This could lead to new therapeutic strategies in patients with overactivation of nervous system and in metabolic syndrome.

4.2. Interactions between Renin-Angiotensin-Aldosterone System and Adipose Tissue. Aldosterone influences insulin metabolism through different mechanisms in cardiovascular and renal tissues, but also in adipose, muscle, and hepatic 
tissues. It is well known that visceral fat produces inflammatory cytokines (adipokines) that take part in systemic inflammation, oxidative stress, and insulin resistance [4]. Some studies suggest that mineralocorticoid receptor in adipocytes facilitate the expression of inflammatory adipokines and stimulate the proadipogenic effect of aldosterone and glucocorticoids. In experimental studies, the inhibition of these receptors reduces the expression of proinflammatory and prothrombotic factors in the adipose tissue and increases the heart and adipose tissue expression of adiponectin.

The adiponectin is a protein produced by the adipose tissue that has beneficial effects on insulin resistance, atherosclerosis, and inflammation. In humans, its levels correlate indirectly with obesity, insulin resistance, diabetic dyslipidemia, and hypertension [51]. This adipokine may be the nexus between metabolic syndrome and cardiovascular disorders. Fallo et al. [31] found lower levels of adiponectin and a lower insulin sensitivity in primary hyperaldosteronism compared with hypertensive subjects with low renin; a negative correlation was found between adiponectin and insulin resistance HOMA index in both groups of patients. A therapeutic approach based on correction of adiponectin levels may improve the insulin sensitivity and lead to a better vascular protection [68]. Furuhashi et al. [69] demonstrated that the inhibition of renin-angiotensinaldosterone system by an angiotensin-converting enzyme inhibitor or angiotensin-receptor blocker increases plasma levels of adiponectin in hypertensive patients. Ronconi et al. [70] found a higher incidence of metabolic syndrome in primary hyperaldosteronism compared with essential hypertension patients. They also analyzed two genetic adiponectine polymorphisms that mark important differences in the metabolic profile of patients.

In addition, the human adipose tissue produces a mineralocorticoid releasing factor not yet identified that stimulates the adrenal production of aldosterone and glucocorticoids [71]. Both hormones interact on the mineralocorticoid receptor increasing adipogenesis and macrophage infiltration, which are two important factors in the development of inflammation in the adipose tissue. The interaction among fat, adrenal cortex, and aldosterone/glucocorticoids may be defined as follows: a rising adiposity, mainly visceral adiposity, induces aldosterone and glucocorticoid production, what in turn facilitates adipogenesis and inflammation of the adipose tissue. A functional prorenin-renin receptor has been described in human adipose tissue, with higher expression levels in visceral than in subcutaneous fat [44]. This receptor may increase the local synthesis of angiotensin II, leading to adipogenesis and adipocyte differentiation $[31,72]$. In vivo studies showed that patients with primary hyperaldosteronism have low levels of adiponectin too, and that it is associated to decreased insulin sensitivity [72]. Losing weight decreases the levels of aldosterone and improves insulin sensitivity both in subjects with normal blood pressure and in hypertensive patients [73].

Finally, cardiovascular protective effects of mineralocorticoid receptor blockers have been described [31, 73]. These protective effects complement the effects of reninangiotensin-aldosterone system blockade, although the risk of hyperkalaemia when using in combination with angiotensin-converting inhibitors or angiotensin II blockers must be considered. Then, the use of drugs from both groups (blocking both systems at the same time) appears to be a promising therapeutic strategy in the treatment of several disorders, such as resistant hypertension, cardiovascular disease, or chronic nephropathy, although more clinical studies are needed.

\section{Aldosterone and Hypertension}

There is a close relationship between aldosterone and hypertension, so hypertension is always present when primary hyperaldosteronism exists. In 1994 Gordon et al. [74] suggested a high prevalence of primary hyperaldosteronism when the aldosterone/plasma renin activity ratio was performed as screening test in hypertensive patients previously considered as cases of essential hypertension; this finding supported primary hyperaldosteronism as the first cause of secondary hypertension. However, subsequent studies [75, 76] did not confirm this high incidence and the suitability of the ratio if no other studies are performed accompanying the test. Beside the role of aldosterone in hypertension, different studies have also examined the relationship between the mineralocorticoid receptor activation by steroids other than aldosterone, mainly cortisol, and hypertension. In this respect, we have previously described that cortisol is the steroid that stimulates the mineralocorticoid receptor in patients with Cushing's syndrome through a mechanism involving the saturation of the enzyme 11-hydroxysteroid dehydrogenase; in this case, a positive effect was observed when plasma levels of cortisol were decreased using ketoconazole; these mechanisms were also found to influence the circadian blood pressure pattern in patients with Cushing's syndrome (loss of the normal day-night blood pressure pattern) [77-79].

Aldosterone conducts its effects through regulation of blood volume and sodium transport. But in addition aldosterone has proven to be involved in changes in the nervous or cardiovascular systems that facilitate the development of hypertension or cardiovascular diseases. Directly or indirectly, aldosterone has influence on the effects of angiotensin II and consequently on the endotheliumdependent vasorelaxation; this is associated to oxidative stress on the vessel wall, leading to reduced availability of nitric oxide. Treatment with spironolactone improves these negative effects [80]. Aldosterone may play an important role in the pathogenesis of cardiovascular diseases by releasing reactive oxygen species, which could be independent on its direct effects on angiotensin II [22]. Some studies suggest that oxidative stress may activate the mineralocorticoid receptor [81]. Aldosterone is involved in vascular damage and synthesis of collagen, facilitating arterial stiffness. Both angiotensin II and aldosterone lead to proliferation and vascular and cardiac remodelling, and both cardiomyocytes and fibroblasts express mineralocorticoid receptor with high affinity for aldosterone and glucocorticoids. Thus, aldosterone may contribute to an abnormal cardiac remodelling mediated by fibrosis and perivascular inflammation. 
Many studies suggest that increased levels of aldosterone in association with obesity and insulin resistance lead not only to sodium retention and volume expansion but also to inflammation and oxidative stress, what at the same time facilitates the development of metabolic syndrome and resistant hypertension [4]. Prevalence of resistant hypertension in patients with primary hyperaldosteronism is $17-22 \%$, higher than in the general hypertensive population. These data suggest a relationship between levels of aldosterone and resistant hypertension. Besides, resistant hypertensive patients without primary hyperaldosteronism have higher levels of aldosterone and high volume expansion [82]. Elevated levels of aldosterone and cortisol in the 24-hour urine sample suggest that corticotropin may act as a common stimulus since this hormone can increase the levels of aldosterone in patients with resistant hypertension [35]. Although the mechanisms by which increased cortisol and aldosterone coexist in resistant hypertension are not well established, some options have been suggested; for example, the enhancement of the sympathetic activity could stimulate both the secretion of aldosterone and cortisol [83]. It has also been described different factors secreted by adipocytes that can increase adrenal secretion of aldosterone; these factors may play a role as potential mediators in the obesity and insulin resistance-related secretion of aldosterone and cortisol $[66,84]$.

Aldosterone (both alone and in combination with angiotensin II) promotes the development of resistant hypertension by producing adaptative changes in cardiovascular, renal and nervous systems. Therefore, aldosterone induces a fast and adverse effect on both vascular smooth muscle and skeletal muscle and enhances the enzyme nicotinamide adenine dinucleotide phosphate oxidase, leading to an excess of reactive oxygen species, redox imbalance, and oxidative stress [8].

In conclusion, the important role of aldosterone in the pathogenesis of the metabolic syndrome, resistant hypertension and cardiovascular diseases is increasingly evident. Overweight and obesity favour the adrenal secretion of aldosterone, what in turn is related to insulin resistance, metabolic syndrome, and increased predisposition to type 2 diabetes mellitus. At present we know that the relationship between renin-angiotensin-aldosterone system and insulin resistance is influenced by complex mechanisms and that the excess of aldosterone has negative effects on carbohydrate metabolism, hypertension, and kidney disorders. Nevertheless, further studies concerning aldosterone and insulin resistance are needed to better establish potential therapeutic strategies. Finally, there is some evidence that support an important role of mineralocorticoid receptor blockers in the treatment of resistant hypertension and in the prevention of cardiovascular diseases in patients with metabolic syndrome and type 2 diabetes mellitus.

\section{References}

[1] C. D. Brown, M. Higgins, K. A. Donato et al., "Body mass index and the prevalence of hypertension and dyslipidemia," Obesity Research, vol. 8, no. 9, pp. 605-619, 2000.
[2] K. G. Alberti, P. Zimmet, and J. Shaw, "The metabolic syndrome-a new worldwide definition," Lancet, vol. 366, no. 9491, pp. 1059-1062, 2005.

[3] D. B. Carr, K. M. Utzschneider, R. L. Hull et al., "Intraabdominal fat is a major determinant of the National Cholesterol Education Program Adult Treatment Panel III criteria for the metabolic syndrome," Diabetes, vol. 53, no. 8, pp. 20872094, 2004.

[4] J. G. Neels and J. M. Olefsky, "Inflamed fat: what starts the fire?" Journal of Clinical Investigation, vol. 116, no. 1, pp. 33$35,2006$.

[5] S. P. Weisberg, D. Hunter, R. Huber et al., "CCR2 modulates inflammatory and metabolic effects of high-fat feeding," Journal of Clinical Investigation, vol. 116, no. 1, pp. 115-124, 2006.

[6] H. N. Ginsberg, "Insulin resistance and cardiovascular disease," Journal of Clinical Investigation, vol. 106, no. 4, pp. 453458, 2000.

[7] S. Stas, A. T. Whaley-Connell, and J. R. Sowers, "Aldosterone and hypertension in the cardiometabolic syndrome," Journal of Clinical Hypertension, vol. 10, no. 2, pp. 94-96, 2008.

[8] S. A. Cooper, A. Whaley-Connell, J. Habibi et al., "Reninangiotensin-aldosterone system and oxidative stress in cardiovascular insulin resistance," American Journal of Physiology, vol. 293, no. 4, pp. H2009-H2023, 2007.

[9] A. Whaley-Connell, M. S. Johnson, and J. R. Sowers, "Aldosterone: role in the cardiometabolic syndrome and resistant hypertension," Progress in Cardiovascular Diseases, vol. 52, no. 5, pp. 401-409, 2010.

[10] J. S. Williams and G. Williams, "50th anniversary of aldosterone," Journal of Clinical Endocrinology and Metabolism, vol. 88, no. 6, pp. 2364-2372, 2003.

[11] F. Verrey, "Early aldosterone action: toward filling the gap between transcription and transport," American Journal of Physiology, vol. 277, no. 3, pp. F319-F327, 1999.

[12] A. Bhargava and D. Pearce, "Mechanisms of mineralocorticoid action: determinants of receptor specificity and actions of regulated gene products," Trends in Endocrinology and Metabolism, vol. 15, no. 4, pp. 147-153, 2004.

[13] M. Kellner, A. Peiter, M. Hafner et al., "Early aldosterone up-regulated genes: new pathways for renal disease?" Kidney International, vol. 64, no. 4, pp. 1199-1207, 2003.

[14] E. Féraille and A. Doucet, "Sodium-potassium-adenosinetriphosphatase-dependent sodium transport in the kidney: hormonal control," Physiological Reviews, vol. 81, no. 1, pp. 345-418, 2001.

[15] R. F. Reilly and D. H. Ellison, "Mammalian distal tubule: physiology, pathophysiology, and molecular anatomy," Physiological Reviews, vol. 80, no. 1, pp. 277-313, 2000.

[16] N. Farman, S. Boulkroun, and N. Courtois-Coutry, "Sgk: an old enzyme revisited," Journal of Clinical Investigation, vol. 110, no. 9, pp. 1233-1234, 2002.

[17] H. Garty, M. Lindzen, R. Scanzano et al., "A functional interaction between CHIF and Na-K-ATPase: implication for regulation by FXYD proteins," American Journal of Physiology, vol. 283, no. 4, pp. F607-F615, 2002.

[18] O. G. Muller, R. G. Parnova, G. Centeno, B. C. Rossier, D. Firsov, and J. D. Horisberger, "Mineralocorticoid effects in the kidney: correlation between alphaENaC, GILZ, and Sgk1 mRNA expression and urinary excretion of $\mathrm{Na}^{+}$and $\mathrm{K}^{+}$," Journal of the American Society of Nephrology, vol. 14, no. 5, pp. 1107-1115, 2003.

[19] S. Boulkroun, M. Fay, M. C. Zennaro et al., "Characterization of rat NDRG2 (N-Myc downstream regulated gene 2), a novel 
early mineralocorticoid-specific induced gene," Journal of Biological Chemistry, vol. 277, no. 35, pp. 31506-31515, 2002.

[20] M. Wehling, M. Christ, and K. Theisen, "Membrane receptors for aldosterone: a novel pathway for mineralocorticoid action," American Journal of Physiology, vol. 263, no. 5, pp. E974-E979, 1992.

[21] J. W. Funder, "The nongenomic actions of aldosterone," Endocrine Reviews, vol. 26, no. 3, pp. 313-321, 2005.

[22] E. L. Schiffrin, "Effects of aldosterone on the vasculature," Hypertension, vol. 47, no. 3, pp. 312-318, 2006.

[23] J. R. Sowers, "Metabolic risk factors and renal disease," Kidney International, vol. 71, no. 8, pp. 719-720, 2007.

[24] N. J. Brown, “Aldosterone and vascular inflammation," Hypertension, vol. 51, no. 2, pp. 161-167, 2008.

[25] B. M. W. Schmidt, U. Sammer, I. Fleischmann, M. Schlaich, C. Delles, and R. E. Schmieder, "Rapid nongenomic effects of aldosterone on the renal vasculature in humans," Hypertension, vol. 47, no. 4, pp. 650-655, 2006.

[26] T. Y. Chun and J. Howard Pratt, "Nongenomic renal effects of aldosterone: dependency on NO and genomic actions," Hypertension, vol. 47, no. 4, pp. 636-637, 2006.

[27] C. Catena, R. Lapenna, S. Baroselli et al., "Insulin sensitivity in patients with primary aldosteronism: a follow-up study," Journal of Clinical Endocrinology and Metabolism, vol. 91, no. 9, pp. 3457-3463, 2006.

[28] P. Milliez, X. Girerd, P.-F. Plouin, J. Blacher, M. E. Safar, and J.-J. Mourad, "Evidence for an increased rate of cardiovascular events in patients with primary aldosteronism," Journal of the American College of Cardiology, vol. 45, no. 8, pp. 1243-1248, 2005.

[29] P. González-Pérez and P. Stiefel, "Increased carotid intimamedia thickness in hypertensive patients with a high aldosterone/plasma renin activity ratio and elevated aldosterone plasma concentration," Journal of Hypertension, vol. 26, no. 7, pp. 1499-1500, 2008.

[30] F. Fallo, F. Veglio, C. Bertello et al., "Prevalence and characteristics of the metabolic syndrome in primary aldosteronism," Journal of Clinical Endocrinology and Metabolism, vol. 91, no. 2, pp. 454-459, 2006.

[31] F. Fallo, P. Della Mea, N. Sonino et al., "Adiponectin and insulin sensitivity in primary aldosteronism," American Journal of Hypertension, vol. 20, no. 8, pp. 855-861, 2007.

[32] G. Giacchetti, V. Ronconi, F. Turchi et al., "Aldosterone as a key mediator of the cardiometabolic syndrome in primary aldosteronism: an observational study," Journal of Hypertension, vol. 25, no. 1, pp. 177-186, 2007.

[33] G. Colussi, C. Catena, R. Lapenna, E. Nadalini, A. Chiuch, and L. A. Sechi, "Insulin resistance and hyperinsulinemia are related to plasma aldosterone levels in hypertensive patients," Diabetes Care, vol. 30, no. 9, pp. 2349-2354, 2007.

[34] M. Bochud, J. Nussberger, P. Bovet et al., "Plasma aldosterone is independently associated with the metabolic syndrome," Hypertension, vol. 48, no. 2, pp. 239-245, 2006.

[35] S. Kidambi, J. M. Kotchen, C. E. Grim et al., "Association of adrenal steroids with hypertension and the metabolic syndrome in blacks," Hypertension, vol. 49, no. 3, pp. 704-711, 2007.

[36] J. Matrozova, O. Steichen, L. Amar, S. Zacharieva, X. Jeunemaitre, and P. F. Plouin, "Fasting plasma glucose and serum lipids in patients with primary aldosteronism: a controlled cross-sectional study," Hypertension, vol. 53, no. 4, pp. 605$610,2009$.

[37] B. M. Egan, V. Papademetriou, M. Wofford et al., "Metabolic syndrome and insulin resistance in the TROPHY sub-study: contrasting views in patients with high-normal blood pressure," American Journal of Hypertension, vol. 18, no. 1, pp. 312, 2005.

[38] J. R. Sowers, A. Whaley-Connell, and M. Epstein, "Narrative review: the emerging clinical implications of the role of aldosterone in the metabolic syndrome and resistant hypertension," Annals of Internal Medicine, vol. 150, no. 11, pp. 776-783, 2009.

[39] M. Ehrhart-Bornstein, K. Arakelyan, A. W. Krug, W. A. Scherbaum, and S. R. Bornstein, "Fat cells may be the obesityhypertension link: human adipogenic factors stimulate aldosterone secretion from adrenocortical cells," Endocrine Research, vol. 30, no. 4, pp. 865-870, 2004.

[40] D. Kraus, J. Jäger, B. Meier, M. Fasshauer, and J. Klein, "Aldosterone inhibits uncoupling protein-1, induces insulin resistance, and stimulates proinflammatory adipokines in adipocytes," Hormone and Metabolic Research, vol. 37, no. 7, pp. 455-459, 2005.

[41] D. Petrasek, G. Jensen, M. Tuck, and N. Stern, "In vitro effects of insulin on aldosterone production in rat zona glomerulosa cells," Life Sciences, vol. 50, no. 23, pp. 1781-1787, 1992.

[42] V. J. Dzau, "Circulating versus local renin-angiotensin system in cardiovascular homeostasis," Circulation, vol. 77, 1, no. 6, pp. I-4-I-13, 1988.

[43] . Min Ae Lee, M. Bohm, M. Paul, and D. Ganten, “Tissue renin-angiotensin systems: their role in cardiovascular disease," Circulation, vol. 87, 4, no. 5, pp. IV7-IV13, 1993.

[44] S. Engeli, R. Negrel, and A. M. Sharma, "Physiology and pathophysiology of the adipose tissue renin-angiotensin system," Hypertension, vol. 35, no. 6, pp. 1270-1277, 2000.

[45] F. Fallo, G. Federspil, F. Veglio, and P. Mulatero, "The metabolic syndrome in primary aldosteronism," Current Hypertension Reports, vol. 9, no. 2, pp. 106-111, 2007.

[46] R. Sarzani, F. Salvi, P. Dessì-Fulgheri, and A. Rappelli, "Reninangiotensin system, natriuretic peptides, obesity, metabolic syndrome, and hypertension: an integrated view in humans," Journal of Hypertension, vol. 26, no. 5, pp. 831-843, 2008.

[47] S. Engeli, K. Gorzelniak, R. Kreutz, N. Runkel, A. Distler, and A. M. Sharma, "Co-expression of renin-angiotensin system genes in human adipose tissue," Journal of Hypertension, vol. 17 , no. 4, pp. 555-560, 1999.

[48] R. Cooper, N. McFarlane-Anderson, F. I. Bennett et al., "ACE, angiotensinogen and obesity: a potential pathway leading to hypertension," Journal of Human Hypertension, vol. 11, no. 2, pp. 107-111, 1997.

[49] D. L. Crandall, H. E. Herzlinger, B. D. Saunders, R. C. Zolotor, L. Feliciano, and P. Cervoni, "Identification and characterization of angiotensin II receptors in rat epididymal adipocyte membranes," Metabolism, vol. 42, no. 4, pp. 511$515,1993$.

[50] S. Umemura, N. Nyui, K. Tamura et al., "Plasma angiotensinogen concentrations in obese patients," American Journal of Hypertension, vol. 10, no. 6, pp. 629-633, 1997.

[51] R. H. Eckel, S. M. Grundy, and P. Z. Zimmet, "The metabolic syndrome," Lancet, vol. 365, no. 9468, pp. 1415-1428, 2005.

[52] S. N. Iyer, M. K. Raizada, and M. J. Katovich, "AT1 receptor density changes during development of hypertension in hyperinsulinemic rats," Clinical and Experimental Hypertension, vol. 18, no. 6, pp. 793-810, 1996.

[53] T. L. Goodfriend, D. L. Ball, B. M. Egan, W. B. Campbell, and K. Nithipatikom, "Epoxy-keto derivative of linoleic acid stimulates aldosterone secretion," Hypertension, vol. 43, no. 2, pp. 358-363, 2004. 
[54] G. H. Goossens, E. E. Blaak, and M. A. Van Baak, "Possible involvement of the adipose tissue renin-angiotensin system in the pathophysiology of obesity and obesity-related disorders," Obesity Reviews, vol. 4, no. 1, pp. 43-55, 2003.

[55] S. Engeli, J. Böhnke, K. Gorzelniak et al., "Weight loss and the renin-angiotensin-aldosterone system," Hypertension, vol. 45, no. 3, pp. 356-362, 2005.

[56] J. Redon, R. Cifkova, S. Laurent et al., "Mechanisms of hypertension in the cardiometabolic syndrome," Journal of Hypertension, vol. 27, no. 3, pp. 441-451, 2009.

[57] G. Grassi, R. Dell'Oro, A. Facchini, F. Q. Trevano, G. B. Bolla, and G. Mancia, "Effect of central and peripheral body fat distribution on sympathetic and baroreflex function in obese normotensives," Journal of Hypertension, vol. 22, no. 12, pp. 2363-2369, 2004.

[58] G. E. Alvarez, S. D. Beske, T. P. Ballard, and K. P. Davy, "Sympathetic neural activation in visceral obesity," Circulation, vol. 106, no. 20, pp. 2533-2536, 2002.

[59] R. S. Ahima, "Adipose tissue as an endocrine organ," Obesity, vol. 14, supplement 5, pp. 242S-249S, 2006.

[60] A. A. da Silva, J. Carmo, J. Dubinion, and J. E. Hall, "The role of the sympathetic nervous system in obesity-related hypertension," Current Hypertension Reports, vol. 11, no. 3, pp. 206-211, 2009.

[61] E. P. Gomez-Sanchez, N. Ahmad, D. G. Romero, and C. E. Gomez-Sanchez, "Is aldosterone synthesized within the rat brain?" American Journal of Physiology, vol. 288, no. 2, pp. E342-E346, 2005.

[62] A. F. De Nicola, C. Grillo, and S. Gonzalez, "Physiological, biochemical and molecular mechanisms of salt appetite control by mineralocorticoid action in brain," Brazilian Journal of Medical and Biological Research, vol. 25, no. 12, pp. 1153-1162, 1992.

[63] R. B. Felder, "Mineralocorticoid receptors, inflammation and sympathetic drive in a rat model of systolic heart failure," Experimental Physiology, vol. 95, no. 1, pp. 19-25, 2010.

[64] A. C. Kontak, Z. Wang, D. Arbique et al., "Reversible sympathetic overactivity in hypertensive patients with primary aldosteronism," Journal of Clinical Endocrinology and Metabolism, vol. 95, no. 10, pp. 4756-4761, 2010.

[65] B. S. Huang, S. Ahmadi, M. Ahmad, R. A. White, and F. H. Leenen, "Central neuronal activation and pressor responses induced by circulating ANG II: role of the brain aldosterone"ouabain" pathway," American Journal of Physiology, vol. 299, no. 2, pp. H422-H430, 2010.

[66] B. S. Huang, R. A. White, M. Ahmad, A. Y. Jeng, and F. H. Leenen, "Central infusion of aldosterone synthase inhibitor prevents sympathetic hyperactivity and hypertension by central Na in Wistar rats," American Journal of Physiology, vol. 295, no. 1, pp. R166-R172, 2008.

[67] M. Ehrhart-Bornstein, V. Lamounier-Zepter, A. Schraven et al., "Human adipocytes secrete mineralocorticoid-releasing factors," Proceedings of the National Academy of Sciences of the United States of America, vol. 100, no. 2, pp. 14211-14216, 2003.

[68] T. W. Kurtz, "New treatment strategies for patients with hypertension and insulin resistance," American Journal of Medicine, vol. 119, no. 5, supplement 5, pp. S24-S30, 2006.

[69] M. Furuhashi, N. Ura, K. Higashiura et al., "Blockade of the renin-angiotensin system increases adiponectin concentrations in patients with essential hypertension," Hypertension, vol. 42, no. 1, pp. 76-81, 2003.
[70] V. Ronconi, F. Turchi, S. Rilli et al., "Metabolic syndrome in primary aldosteronism and essential hypertension: relationship to adiponectin gene variants," Nutrition, Metabolism and Cardiovascular Diseases, vol. 20, no. 2, pp. 93-100, 2010.

[71] C. Guo, V. Ricchiuti, B. Q. Lian et al., "Mineralocorticoid receptor blockade reverses obesity-related changes in expression of adiponectin, peroxisome proliferator-activated receptor-gamma, and proinflammatory adipokines," Circulation, vol. 117, no. 17, pp. 2253-2261, 2008.

[72] V. Lamounier-Zepter and M. Ehrhart-Bornstein, "Fat tissue metabolism and adrenal steroid secretion," Current Hypertension Reports, vol. 8, no. 1, pp. 30-34, 2006.

[73] M. L. Tuck, J. Sowers, and L. Dornfeld, "The effect of weight reduction on blood pressure, plasma renin activity, and plasma aldosterone levels in obese patients," New England Journal of Medicine, vol. 304, no. 16, pp. 930-933, 1981.

[74] R. D. Gordon, M. Stowasser, T. J. Tunny, S. A. Klemm, and J. C. Rutherford, "High incidence of primary aldosteronism in 199 patients referred with hypertension," Clinical and Experimental Pharmacology and Physiology, vol. 21, no. 4, pp. 315-318, 1994.

[75] N. M. Kaplan, "The current epidemic of primary aldosteronism: causes and consequences," Journal of Hypertension, vol. 22, no. 5, pp. 863-869, 2004.

[76] P. Stiefel, R. Aparicio, J. Carneado, E. Pamies, and J. Villar, "The current epidemic of primary aldosteronism: causes and consequences," Journal of Hypertension, vol. 22, no. 10, pp. 2040-2042, 2004.

[77] P. Stiefel, J. S. García-Morillo, L. Jimenez et al., "Role of ketoconazole treatment in urinary-free cortisol-to-cortisone and tetrahydrocortisol-to-tetrahydrocortisone ratios in nonectopic Cushing's syndrome," Endocrine, vol. 18, no. 3, pp. 279284, 2002.

[78] P. Stiefel and J. Carneado, "Cortisol, aldosterona y diferentes formas de hipertensión: papel de la 11-beta-hidroxiesteroide dehidrogenasa," Hipertensión, vol. 17, no. 4, pp. 161-168, 2000.

[79] J. Gimenez, P. Stiefel, M. L. Miranda et al., "The dispersion quotients: a new approach for evaluating the blood pressure profile in essential versus Cushing's syndrome hypertensive patients," Annals of the New York Academy of Sciences, vol. 783, pp. 321-323, 1996.

[80] K. K. Gaddam, M. K. Nishizaka, M. N. Pratt-Ubunama et al., "Characterization of resistant hypertension: association between resistant hypertension, aldosterone, and persistent intravascular volume expansion," Archives of Internal Medicine, vol. 168, no. 11, pp. 1159-1164, 2008.

[81] G. E. Callera, R. M. Touyz, R. C. Tostes et al., "Aldosterone activates vascular p38MAP kinase and NADPH oxidase via cSrc," Hypertension, vol. 45, no. 4, pp. 773-779, 2005.

[82] A. Prasad and A. A. Quyyumi, "Renin-angiotensin system and angiotensin receptor blockers in the metabolic syndrome," Circulation, vol. 110, no. 11, pp. 1507-1512, 2004.

[83] H. Hitomi, H. Kiyomoto, A. Nishiyama et al., "Aldosterone suppresses insulin signaling via the downregulation of insulin receptor substrate-1 in vascular smooth muscle cells," Hypertension, vol. 50, no. 4, pp. 750-755, 2007.

[84] D. W. Wray and M. A. Supiano, "Impact of aldosterone receptor blockade compared with thiazide therapy on sympathetic nervous system function in geriatric hypertension," Hypertension, vol. 55, no. 5, pp. 1217-1223, 2010. 


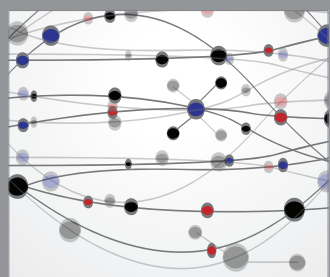

The Scientific World Journal
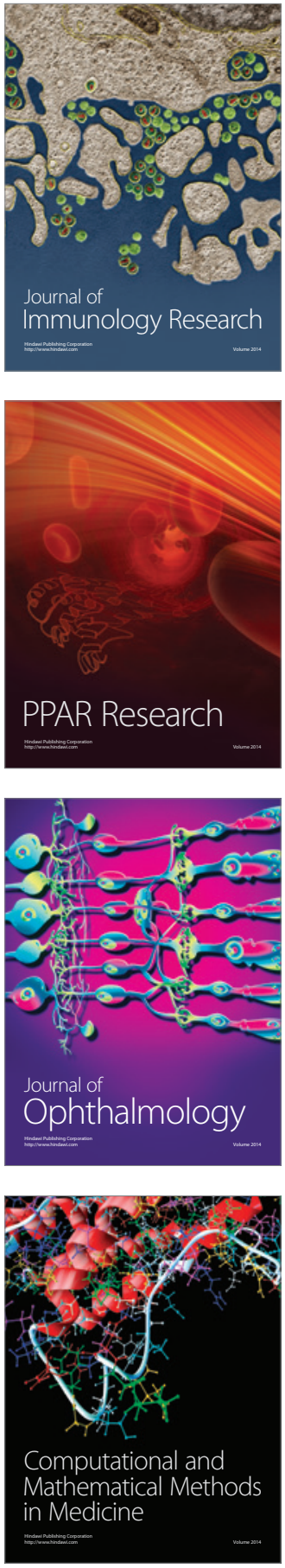

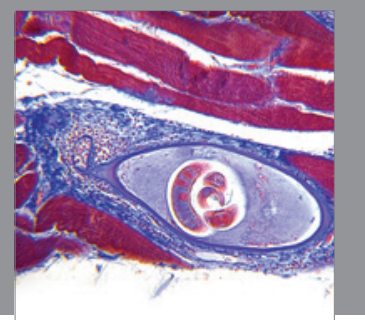

Gastroenterology

Research and Practice
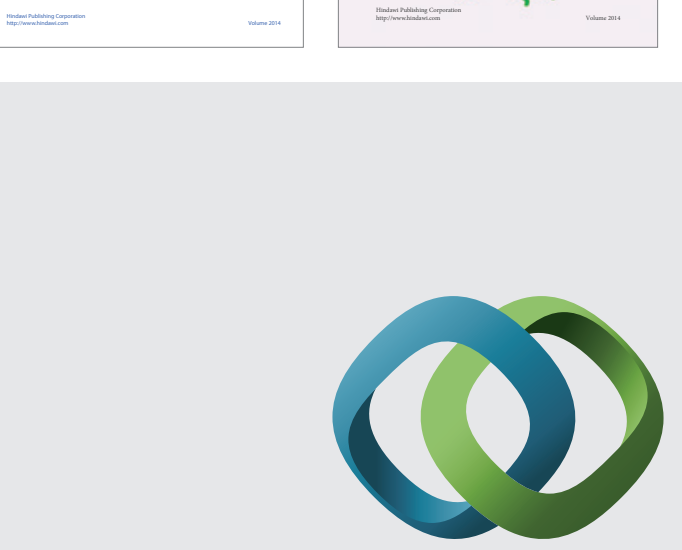

\section{Hindawi}

Submit your manuscripts at

http://www.hindawi.com
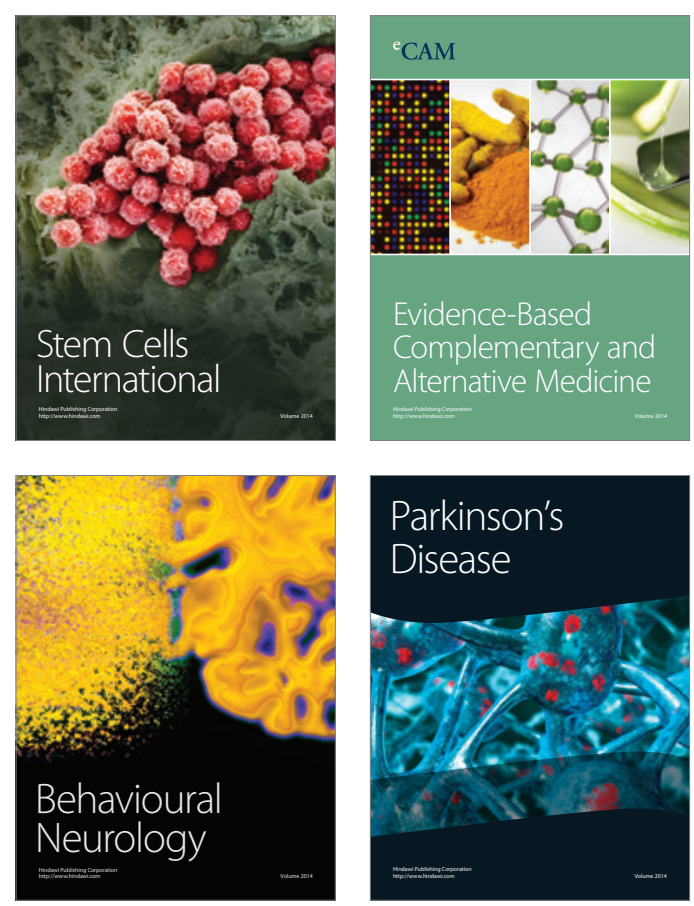

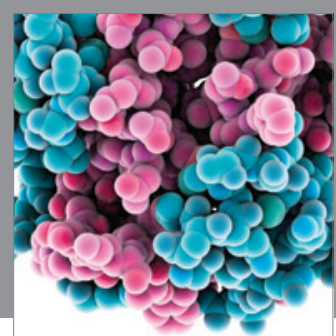

Journal of
Diabetes Research

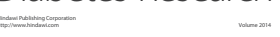

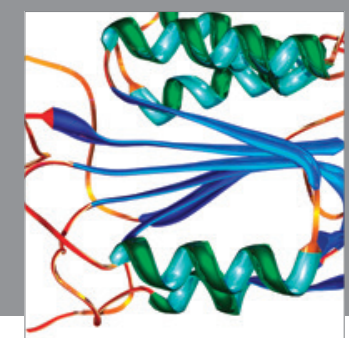

Disease Markers
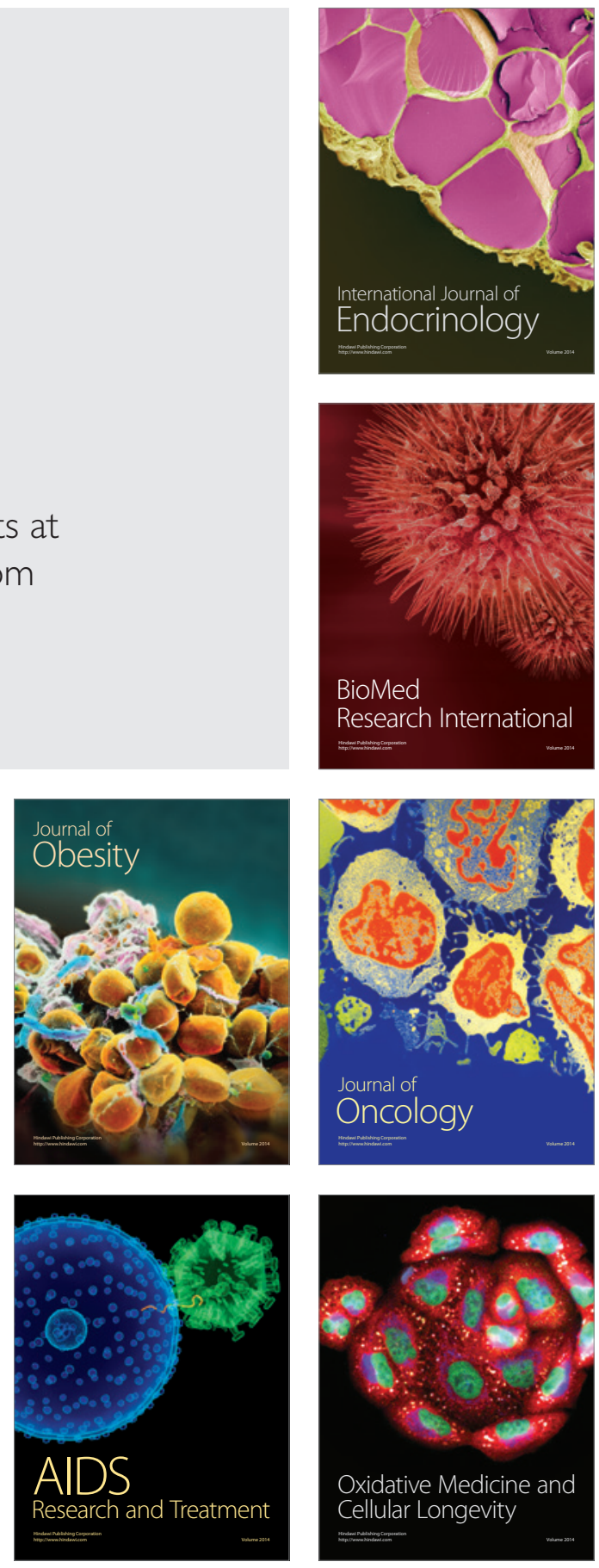